\title{
CANOAS VIGILENGAS E A DINÂMICA DA PESCARIA EM VIGIA, PARÁ: SABERES E PRÁTICAS CULTURAIS DA PESCA ARTESANAL
}

\author{
TRADITIONAL VESSEL AND THE FISHING DYNAMICS IN VIGIA, PARÁ: \\ KNOWLEDGE AND CULTURAL PRACTICES OF ARTISANAL FISHING
}

\section{LA BUQUE TRADICIONAL Y DINÁMICA DE LA PESCA EN VIGIA, PARÁ: CONOCIMIENTO Y PRÁCTICAS CULTURALES DE LA PESCA ARTESANAL}

\begin{abstract}
Resumo
O presente estudo analisa práticas culturais desenvolvidas a partir das construções de canoas artesanais na região do município de Vigia no Estado do Pará, levanta reflexões sobre a dinâmica da pescaria a partir da utilização e produção por carpinteiros destas canoas, denominadas de vigilengas. Neste sentido objetivamos identificar saberes e conhecimentos tradicionais de pescadores e carpinteiros artesanais que circulam em suas relações, analisando as consequências do paradigma da modernidade sobre a prática cultural da pescaria. Trata-se de estudo que envolve pesquisa bibliográfica, de campo e entrevistas semiestruturadas, com abordagem qualitativa e com análise de conteúdo. Justifica-se o estudo em virtude da importância histórica e cultural que a pescaria possui nestas regiões da Amazônia envolvendo comunidades tradicionais no uso de canoas artesanais. Entre os resultados verificou-se uma interação socioambiental na construção das canoas vigilengas, assim como na prática da pescaria artesanal contribuindo para a circulação de saberes e conhecimentos tradicionais, portando as mudanças sociais, impuseram novas regras às práticas de pescaria com canoas motorizadas, ocasionando o sumiço da canoa vigilenga. Desta forma conclui-se identificando que nas relações canoa vigilenga, pescadores e carpinteiros circularam relações de saberes, pertencimento e identidade local.
\end{abstract}

Palavras-chave: Pesca Artesanal; Carpintaria; Conhecimentos Tradicionais.

\begin{abstract}
The present study analyzes cultural practices developed from the construction of artisanal canoes in the region of the municipality of Vigia in the State of Pará, raises reflections on the dynamics of fishing from the use and production by carpenters of these vessels (canoes), called vigilengas. In this sense, we aim to identify traditional knowledge and knowledge of fishermen and artisanal carpenters who circulate in their relationships, analyzing the consequences of the modernity paradigm on the cultural practice of fishing. This is a study that involves bibliographic, field research and semi-structured interviews, with a qualitative approach and content analysis. The study is justified due to the historical and cultural importance that fisheries have in these regions of the Amazon involving traditional communities in the use of artisanal canoes. Among
\end{abstract}

\footnotetext{
${ }^{1}$ Pedagogo, mestrando no Programa de Pós-graduação em Estudos Antrópicos na Amazônia, Universidade Federal do Pará, pesquisador no Grupo de Pesquisa em Estudos Socioambientais Costeiros da UFPA e no Grupo de Pesquisa em Educação e Meio Ambiente na UEPA. E-mail: mailsolima@bol.com.br

${ }^{2}$ Historiador, mestrando no Programa de Pós-graduação em Estudos Antrópicos na Amazônia, Universidade Federal do Pará, pesquisador no Grupo de Pesquisa História em Campo da UFPA. E-mail: paulocordeirovigia@gmail.com
} 


\section{Canoas vigilenas e a dinâmica da pescaria em Vigia, Pará: \\ Saberes e práticas culturais da pesca artesanal}

the results, there was a socio-environmental interaction in the construction of vigilenga canoes, as well as in the practice of artisanal fishing, contributing to the circulation of traditional knowledge and knowledge, thus bringing about social changes, imposing new rules on fishing practices with motorized canoes, causing the disappearance of the vigilenga canoe. Thus, it concludes by identifying that in the canoe vigilenga relations, fishermen and carpenters circulated relations of knowledge, belonging and local identity.

Key words: Artisanal Fishing; Carpentry; Traditional knowledge.

\section{Resumen}

El presente estudio analiza las prácticas culturales desarrolladas a partir de la construcción de canoas artesanales en la región del municipio de Vigia en el estado de Pará, plantea reflexiones sobre la dinámica de la pesca a partir del uso y la producción por parte de los carpinteros de estas canoas, llamadas vigilengas. En este sentido, nuestro objetivo es identificar el conocimiento tradicional y el conocimiento de los pescadores y carpinteros artesanales que circulan en sus relaciones, analizando las consecuencias del paradigma de la modernidad en la práctica cultural de la pesca. Este es un estudio que involucra bibliografía, investigación de campo y entrevistas semiestructuradas, con un enfoque cualitativo y análisis de contenido. El estudio se justifica debido a la importancia histórica y cultural que tienen las pesquerías en estas regiones del Amazonas, involucrando a las comunidades tradicionales en el uso de canoas artesanales. Entre los resultados, hubo una interacción socioambiental en la construcción de canoas vigilenga, así como en la práctica de la pesca artesanal, contribuyendo a la circulación del conocimiento y el conocimiento tradicional, provocando cambios sociales, imponiendo nuevas reglas sobre las prácticas de pesca con canoas motorizadas, causando la desaparición de la canoa vigilenga. De esta forma, concluimos identificando que en la canoa vigilenga las relaciones, pescadores y carpinteros circulaban relaciones de conocimiento, pertenencia e identidad local.

Palabras clave: Pesca artesanal; Carpinteria; Conocimientos tradicionales.

\section{INTRODUÇÃO}

A região Amazônica no norte do Brasil possui uma diversidade de práticas culturais desenvolvidas por comunidades tradicionais locais, que constituem formas próprias de subsistências que atravessaram séculos produzindo saberes e conhecimentos tradicionais que se relacionam com seus cotidianos, sendo repassados por gerações, muitas vezes como forma de sobrevivências.

Entre estas práticas destaca-se a de pescadores, por serem uma das atividades mais antigas desenvolvidas na região amazônica, que segundo Diegues (1999) a prática da pesca já era utilizada pelos índios antes da chegada dos navegadores europeus ao Brasil.

Portanto, a pesca desenvolvida inicialmente pelos índios, se tornará práticas cotidianas e estratégicas de sobrevivências para comunidades amazônidas, em face de suas ocupações seculares à beira de rios, mar e igarapés, seja nas cidades, vilas ou povoados tornando-se importante espaço de circulação de saberes e conhecimentos tradicionais, a partir de uma profunda articulação com a natureza, sendo a água elemento cultural determinante (LOUREIRO, 1992).

Além disso, a partir da pesca se originam outras práticas culturais que se desenvolvem em meio a saberes e conhecimentos necessários aos afazeres da pescaria, tais como produção de utensílios, apetrechos e a construção artesanal de canoas utilizadas em pesca ao mar.

Dentro desta perspectiva que este estudo emerge, visando analisar os saberes e conhecimentos tradicionais que circulavam na dinâmica do uso de canoas artesanais no município de Vigia no Estado do Pará, 


\section{Canoas vigilenas e a dinâmica da pescaria em Vigia, Pará: \\ Saberes e práticas culturais da pesca artesanal}

a partir de relações dos pescadores e carpinteiros artesanais com as construções destas canoas, conhecidas com vigilengas, como objetivos específicos constaram os de investigar como ocorria a dinâmica da produção de canoas vigilengas e identificar práticas culturais desenvolvidas no processo de construção destas canoas.

O munícipio de Vigia está localizado na mesorregião nordeste do Pará, microrregião do salgado, com uma área territorial de 401, $589 \mathrm{~km}^{2}$, possuindo diversos distritos como o de Vigia (sede), Santa Rosa, Itapuã, Barretas, Cumaru, Porto Salvo e Penha Longa, sua população está estimada em 53.686 habitantes (IBGE, 2019). Vigia é um dos municípios mais antigos do Estado do Pará, com uma localização estratégica e sua história ligada a colonização portuguesa (CORDEIRO, 2013).

Do ponto de vista econômico o município de Vigia desenvolve forte atividade pesqueira, com pesca artesanal, industrial e a extração de caranguejo, considerado um dos maiores polos de desembarque de pescado do Estado do Pará, possuindo ainda atividades agrícolas como formas de subsistências de comunidades tradicionais (LOUREIRO, 1985).

Portanto, em meio à estas características do município de Vigia e de sua formação histórica que realizamos este trabalho, que se desenvolve a partir de estudo bibliográfico na qual utilizamos com fonte de pesquisa Benttendorff (1990), João Daniel (2004), José Verissimo (1895) e Loureiro (1992;1985), assim como estudos de autores como Diegues (1999; 2004; 2010) e Leff (2007; 2019), entre outros.

Realizamos ainda trabalho de campo com entrevistas semiestruturadas (BRANDÃO, 2007) procurando estabelecer um contato mais próximo e dinâmico sobre o objeto de estudo, nossa abordagem é qualitativa (FLICK, 2013) com análise de conteúdo (BARDIN, 2011).

Assim sendo, o estudo ao abordar questões ligadas aos saberes e conhecimentos tradicionais de pescadores e carpinteiros artesanais, permitiu que realizássemos uma discussão sobre a produção de conhecimentos alternativos à lógica do pensamento único praticada pelo paradigma da sociedade moderna civilizada.

Para Leff (2007), a lógica do paradigma da modernidade se assenta no advento do capitalismo que vem modificando as relações entre os conhecimentos, dividindo-os entre os teóricos e os saberes práticos, surgindo dessa maneira uma perspectiva de conhecimento único, o da ciência moderna com a institucionalização da racionalidade econômica, que visa o desenvolvimentismo e a industrialização.

Esta perspectiva impacta diretamente nas comunidades tradicionais, como a de pescadores e carpinteiros artesanais de Vigia, ao provocar mudanças nas relações sociais de seus cotidianos, pois, como destaca Leff (2007):

Na história humana todo saber, todo conhecimento sobre o mundo e sobre as coisas, tem estado condicionado pelo contexto geográfico, ecológico e cultural em que produz e se reproduz uma formação social determinada. As práticas produtivas, dependentes do meio ambiente e da estrutura social das diferentes culturas geraram formas de percepção e técnicas específicas para a apropriação social da natureza e da transformação do meio (LEFF, 2007, p. 23). 


\section{Canoas vigilenas e a dinâmica da pescaria em Vigia, Pará: \\ Saberes e práticas culturais da pesca artesanal}

Assim sendo, este estudo se articula em reflexões de ambientes e cenários históricos diferenciados de produção de conhecimentos, como os espaços de estaleiros que carpinteiros artesanais em Vigia produziam as canoas vigilengas.

Por certo, que estes cenários sofrem interferências da perspectiva desenvolvimentista e do contexto imposto pelo sistema capitalista, que avançou na região introduzindo novos atores e elementos na pescaria, como a canoa motorizada e a pesca industrial (LOUREIRO, 1985).

Neste sentido, nossa abordagem parte da problematização das origens das canoas vigilengas e suas técnicas de construções como formas de circulação de saberes e conhecimentos tradicionais, diante de um panorama de interdependências e interações entre pescadores, carpinteiros artesanais e o ambiente natural.

O ambiente natural, se torna neste contexto um espaço de disputa por concepções diferenciadas de sociedade, para os pescadores e carpinteiros artesanais como fontes de interação e subsistências, para o paradigma capitalista objeto a ser transformado em mercadoria para obtenção de lucros.

Assim, ao procurarmos dar visibilidades aos conhecimentos e saberes de práticas culturais de carpinteiros artesanais na construção das canoas vigilengas, apontamos para que se possa enfrentar o silenciamento imposto pela racionalidade hegemônica que subjugam estas práticas culturais como inferiores na Amazônia.

\section{PROCEDIMENTOS METODOLÓGICOS}

Iniciamos este estudo por meio de pesquisa bibliográfica com base em Marconi e Lakatos (2017), onde, fontes secundárias documentais e bibliográficas publicadas por autores clássicos e contemporâneos subsidiaram o trabalho procurando nos colocar em contato direto com o objeto do estudo.

Logo, a pesquisa bibliográfica nos forneceu diferentes informações, como históricas, clássicas e cotidianas sobre a pescaria e a confecção de canoas no município de Vigia, tornando possível explorar a temática sobre novos enfoques, buscando atingir os objetivos do trabalho, exigindo rigor em nossas reflexões sobre a manipulação das informações para que estas não se tornassem meras repetições de questões já tratadas por outros trabalhos (MARCONI; LAKATOS, 2017).

O trabalho de campo com base Brandão (2007) consistiu em realizar levantamento da prática cultural local das confecções das canoas, objetivando identificar as dinâmicas realizadas em estaleiros artesanais e as formas de produção de saberes e conhecimento tradicionais nestes espaços.

Portanto, ainda como procedimento de trabalho de campo realizamos observações e entrevistas semiestruturada, que envolveram interlocutores ligados a pesca e a carpintaria artesanal no município de Vigia, nesta técnica procuramos estabelecer vivências com o objeto e os sujeitos da pesquisa para garantir aprofundamento das questões do estudo.

O tratamento dos dados da pesquisa partiu da perspectiva de análise de conteúdo (BARDIN, 2011), na qual realizamos pré-análise e descrição analítica das questões pesquisadas, e por meio de abordagem qualitativa (FLICK, 2013) procuramos desenvolver uma análise reflexiva das relações sociais estabelecidas 


\section{Canoas vigilenas e a dinâmica da pescaria em Vigia, Pará: \\ Saberes e práticas culturais da pesca artesanal}

pelas práticas culturais das construções de canoas e da pesca artesanal no município de Vigia, assim como, de questões contemporâneas que envolvem o uso das canoas e a dinâmica atual da pesca na região em estudo.

\section{AS CANOAS VIGILENGAS E OS ESTALEIROS ARTESANAIS NO SÉCULO XIX NO MUNÍCIPIO DE VIGIA/PA}

As pequenas produções agrícolas e pesqueiras, sempre foram responsáveis pela estruturação econômica do município de Vigia, portanto, alternadamente em relação as safras agrícolas e pesqueiras, tinha-se a força de trabalho familiar que se nucleava em torno de uma dessas atividades, sem o abandona da outra (LOUREIRO, 1985).

Segundo Loureiro (1985, p. 22), "sobressaíam no conjunto dessas circunstâncias: o caráter artesanal dos meios de produção (que ainda hoje responde pela designação de pescadores artesanais), cujos materiais básicos se encontravam livres na natureza até quase meados deste século".

Neste sentido, a partir da pesca artesanal pode-se perceber grandes contribuições para a produção pesqueira nas águas litorâneas e costeiras no Brasil, com destacada relevância social e econômica, principalmente pelo fato dos pescadores artesanais possuírem relações diretas com ecossistemas aquáticos e vastos conhecimentos e saberes acerca do meio natural da região onde vivem, os quais, ao longo dos anos tem sido repassado culturalmente, entre gerações de pescadores (DIEGUES, 1999; LOUREIRO, 1985).

Assim, analisando a importância da pesca artesanal no município de Vigia que encontramos as canoas Vigilengas e os estaleiros artesanais que realizavam suas construções e consertos, como espaços de circulação de saberes e conhecimentos tradicionais, constituindo uma peculiar característica da estrutura pesqueira na região.

Não restam dúvidas que diversas pesquisas como de Loureiro (1985) e Jose' Verissimo (1895), tem contribuindo para um olhar diferenciado sobre esta pesca regional, como uma prática cultural secular no município de Vigia,

Portanto, por possuir uma dinâmica de dependência ligada as questões fluviais, esta prática cultural se desenvolve inicialmente com o uso de canoas construídas artesanalmente, contexto este, que permite uma interação direta das comunidades locais com a natureza, transformando estas interações as condições propícias para a produção dos seus conhecimentos tradicionais.

Para Diegues e Pereira (2010) o contexto da produção dos conhecimentos tradicionais é fundamental para o desenvolvimento de suas interpretações e assim, se contrapor à padronização e fragmentação imposta pela ciência moderna.

Dentro desta perspectiva que identificamos nas crônicas de Benttendorff (1990), um padre jesuíta que percorreu a região ao longo de trinta anos, de 1663 a 1693, os primeiros traços de existência de estaleiros na região de Vigia.

O termo "estaleiro", ainda hoje é empregado para referir-se a pequenas oficinas instaladas em fundos de quintais, destinado à fabricação de embarcações (LOUREIRO, 1985). 


\section{Canoas vigilenas e a dinâmica da pescaria em Vigia, Pará: \\ Saberes e práticas culturais da pesca artesanal}

Assim, de acordo com a Crônica do padre Benttendorff (1990), no final do século XVII, já havia no aldeamento jesuítico de Mamaiacu (hoje vila de Porto Salvo distrito de Vigia), um estaleiro que atuava na fabricação e conserto de canoas, a crônica cita que:

[...] João Valladão, o qual estava ensinando com muito agrado no Pará, de onde também veio o Padre Ignacio Ferreira com os seus discípulos futuros, que estavam daquela banda em companhia do governador, se bem com pouca feliz viagem, porque além de se terem quase alagados os padres nas Barretas, da banda da Vigia, e terem sido obrigados de arribar para concertar sua canoa na roça de Mamayacu" (Grifo nosso) (BENTTENDORFF, 1990, p. $67)$.

Segundo esta crônica a canoa que levava o padre Ignácio Ferreira e seus discípulos juntamente com o

Governador da Província se chocou com pedras, sendo levada para o aldeamento de Mamaiacu, para realizar o concerto, o que evidencia o uso secular de pequenos estaleiros.

Certamente que não se percebe a palavra estaleiro na crônica do padre Benttendorff (1990), entretanto esse termo é descrito em uma passagem da obra de outro missionário, o padre jesuíta João Daniel (2004), contemporâneo de Benttendorff, o qual, viveu entre 1741 e 1757 na Amazônia, deixando relatos históricos de seus descobrimentos sobre a região em suas crônicas.

João Daniel foi um padre jesuíta português que viajou para o Estado do Maranhão e GrãoPará no ano de 1741, com apenas 19 anos. Terminou sua formação no Colégio Máximo de S. Luiz e atuou como missionário até seu exílio, junto com outros membros da Companhia de Jesus, em 1757. Foi enviado para a prisão em Portugal, onde permaneceu até sua morte no ano de 1775 (PASCHOAL, 2019, p. 10).

Assim, o padre João Daniel (2004), descreve que:

O feitio do estaleiro são paus atravessados bem do feitio de tesouras abertas com as pontas metidas (na terra), e as pontas de cima bem seguras em esteios, ou estacas, distantes cada tesoura das outras (DANIEL, 2004, p. 51).

Observa-se na crônica do jesuíta as características artesanais que envolviam as construções nos estaleiros e a preparação técnica ligada aos conhecimentos tradicionais dos carpinteiros, que passaram a serem conhecidos como mestres, o que pode ser percebido no trecho a seguir, no qual, o religioso destaca que:

[...] para fazer alguma canoa grande, se elegem para isso um grande madeiro, e de pau muito grande, e duro, que para se poder manusear, e levar, e conduzir ao estaleiro necessita de muita gente, de bons mestres, de oficiais práticos, e bons operários (DANIEL, 2004, p. 51).

Portanto, verificamos no relato de João Daniel (2004) que a dinâmica do trabalho artesanal desenvolvido nos estaleiros requeria, além de trabalho técnico especializado, o conhecimento integrado sobre a vegetação local, para o reconhecimento das madeiras propícias da floresta a serem utilizadas nas construções das canoas.

Neste contexto, Cardoso (2008) ao analisar o recenseamento do Grão-Pará do ano de 1778, ressalta que após exatamente 19 anos da expulsão dos jesuítas da vila de Vigia, já era possível se identificar os ofícios de carpinteiros de canoas e de calafate, o que realça a importância desta atividade artesanal na região envolvendo os missionários. 


\section{Canoas vigilenas e a dinâmica da pescaria em Vigia, Pará: \\ Saberes e práticas culturais da pesca artesanal}

Cardoso (2008), relata que além das questões religiosas os jesuítas foram responsáveis pela manutenção da cultura hegemônica europeia na região e a formação de mão de obra local, onde:

[...] as crônicas dos padres mostram o papel importante que os missionários tiveram na formação da mão-de-obra, o que por um lado garantiu o sucesso da imposição do modelo europeu de cultura, descrevendo com segurança o amplo trabalho executado nas missões e revelando igualmente a aprendizagem comum de índios e de negros (CARDOSO, 2008, p. $82)$.

Portanto, estas aprendizagens impostas pelos jesuítas aos índios e negros somadas aos saberes destes grupos sociais, contribuíram para a construção dos conhecimentos sobre a produção de canoas em estaleiros artesanais na região do município de Vigia, o que tornou possível, a partir da técnica de construir canoas, que as comunidades locais tivessem condições de sobrevivências em interação com o ambiente natural.

Entre as formas de interação pode-se citar a pescaria de subsistências e a agilidade para se deslocar pelos rios, igarapés e o mar, por meio de canoas, tornando assim a construção das canoas conhecidas como vigilengas uma necessidade para a comunidade local.

Estas canoas apresentarão em sua estrutura as características dos barcos dos colonizadores e os traços tradicionais das canoas indígenas como destaca José Verissimo (1895), em que:

Nas grandes canôas chamadas de vigilengas, talvez porque na ribeira da Vigia fossem de primeiro construídas, saém elles, canoeiros habilíssimos e ousados, ao alto mar. A vigilenga é a canoa mestiça, o resultado da combinação, para não dizer do cruzamento, entre o barco de pesca portuguez e a igaraté, a canôa grande (igara, canôa été grande) do indígena brazileiro (JOSÉ VERISSIMO, 1895, p. 89).

Assim sendo, o processo de aprendizagem que circulava em práticas culturais da produção da canoa "mestiça", se constituiu em um ritual de significações e apropriação subjetiva de saberes, permitindo a construção do que Leff (2019), aponta como processos pessoais de assimilação que cada sujeito faz de determinada cultura, gerando e concretizando conhecimentos e saberes tanto individuais como coletivos.

Desta forma, estes saberes que envolvem a produção das canoas artesanais irão permitir que seus praticantes se apropriem de técnicas e conhecimentos em uma simbiose entre a natureza e seus processos de produção, em uma estratégia central, a sobrevivência e melhores condições em suas vidas, para isto, a pescaria artesanal será um fator impulsionador da dinâmica de construção destas canoas.

Esta pesca artesanal através das canoas vigilengas na região de Vigia já se destaca desde o período colonial, abastecendo navegadores e os Governos locais (VERISSMO, 1895; DANIEL, 2004).

Neste sentido, as características do município de Vigia vinculado à prática da pescaria, principalmente por ser banhado por uma bacia hidrográfica extensa na Amazônia, envolvendo o Oceano Atlântico, permitiu que as práticas tradicionais de construir as canoas vigilengas, se tornasse no século XIX uma prática social ligada ao discurso do desenvolvimento econômico local, em que:

A canoa, também, não forçoso seja aquela descrita, mais especialmente na pescaria usada e por isso chamada de canoa de pesca. Servem-se de qualquer quando é preciso e veem-se grandes montarias e também igarités ocupadas na pesca. Estas, todavia, não têm as vantagens daquelas, o silencioso deslizar, o velóz correr, o manejo fácil, a evolução rápida, e 


\section{Canoas vigilenas e a dinâmica da pescaria em Vigia, Pará: Saberes e práticas culturais da pesca artesanal}

possibilidade de entrar e mover-se nos mais estreitos e mais rasos riachos e lagos, de encostar às beiras mais baixas e até de ser varada ou levada aos empuxões, de uma daquelas bacias para outra, através e sobre os esteios de capim que as separam (VERISSIMO, 1895, p. 31).

Desta forma, a produção das canoas vigilengas será identificada pelas suas características locais como uma canoa da região, que mesmo ao incorporar determinados aspectos do barco português, será da canoa indígena, igarité, suas fontes de pertencimento e de identidade cultural própria de Vigia, o que é realçado pela presença dos rituais indígenas em suas construções, conforme José Verissimo (1895), constata que:

A madeira para a canoa, e suas florestas lhes fornecem variadas e excelentes, há de ser cortada em determinada lua, consoante certa orientação, e não deve a abertura do casco ser presenciada por mulher pejada, o que faria rachar [...]. No preparo do casco usam ainda o fogo, como indígena primitivo, não só para consumir a porção de madeira que lhes daria muito trabalho tirar com a ferramenta, como depois de assim cavado o madeiro, para abrir e dar ao tronco concavo a forma e jeito conveniente. (VERISSIMO, 1895, p. 32).

Logo, como identifica Verissimo (1895), os traços dos rituais de construções dos povos originários indígenas, de madeira única em forma de casco, tornam evidente suas contribuições para a formação social na região de Vigia, contribuindo fortemente para a prática cultural de construções das canoas locais.

Destaca-se assim, que as técnicas tradicionais desenvolvidas por carpinteiros artesanais nas construções das canoas em Vigia, incorporaram os traços indigenas e compreendem noções de saberes práticos inferidos nas suas próprias empirias, desenvolvendo cálculos, analisando dimensões e projetando formatos para lhes dar ao produto final melhores condições de trafegabilidade no mar.

Além disso, visando melhorar a trafegabilidade estas canoas passam a incorporar construções mais complexas, como os elementos presentes nos barcos portugueses, diferente do uso da madeira única, das construções indígenas, sobre as técnicas de construção verifica-se que:

Para isso poem-o com a abertura para baixo sobre uns paos, abre de dispostos e acendem-lhe em baixa fogo, cujo calor dilatando a madeira facilita-lhes a operação de a afeiçoarem em forma de canoa, mediante paos de vários tamanhos que introduzem de lado a lado dos bordos internos para forçar a distenção e para conseva-la distendida e de embiras e cipós, passados à volta, a fim de regular a distensão e evitar se não abra no sentido do cumprimento a larga prancha curva. Destarte promto o casco, aperfeiçoam-se com ferramentas de carpintaria, adapatan-lhes as ridélas de popa e proa. [...] a estopa e o breu pra lhe tomas alguma raxa e os interstícios das ligações fornecelho-os na própria mata (VERISSIMO, 1895, p. 32-33).

Há de se considerar que no regime colonial o ofício da carpintaria naval já possuía práticas diferenciadas, onde a produção de navios, era a única que possuía ajudantes, os negros livres ou na condição de escravizados, com estaleiros maiores por causa da grande estrutura necessária e a produção de canoas menores como as vigilengas eram construídas em estaleiros localizados em quintais ou em áreas de uso comum (CARDOSO, 2008; BAENA, 1969).

A produção e o uso das canoas e outras embarcações gerou a necessidade constante de um outro profissional, o de calafate, que era uma atividade desenvolvida pelos negros por ser considerada um ofício subalterno à época, segundo aborda Cardoso (2008), mesmo sendo uma atividade importante para a durabilidade das canoas. 


\section{Canoas vigilenas e a dinâmica da pescaria em Vigia, Pará: \\ Saberes e práticas culturais da pesca artesanal}

O calafate se constituía em uma técnica de trabalho artesanal desenvolvido com o objetivo de garantir a preservação e manutenção das canoas, a atividade desenvolvida era de tapar as brechas das canoas com algodão emudecido envolto de breu, uma resina coletada por meio de secreções de plantas da floresta que eram fervidos em latões e/ou outros recipientes para impermeabilizar, atividade que com o passar do tempo incorporou-se a utilização de produtos industrializados, extinguindo nesta técnica o uso dos recursos da floresta.

A atividade de calafate, como oficio desde à época da colonização, tornou-se em Vigia uma importante fonte de renda para a população mais pobres principalmente a população negra, refletindo a divisão social imposta pela presença dos colonos europeus que ocuparam as margens dos rios favorecidos pelas sesmarias (VELOSO, 2016).

Esta prática se expandiu no município, sendo desenvolvida em diversos espaços em Vigia, o que ocasionou sua regulamentação pelo Código de Posturas Municipal de 1883, passando a ter limitações ao uso de locais públicos para sua realização, assim o código impôs que:

Art. 26 - O calafeto, construção ou conserto de canoas ou de qualquer embarcação só fará no porto denominado das "Bravas", entre a "Ribeira" e o "Caes" e no porto denominado de "Pombal", no canto da casa do proprietário Joaquim Manoel de Carvalho, lado Sul, até o lado do Norte da casa do proprietário José de Mello Palheta e Vasconcelos. O contraventor incorrerá na multa de $20 \$ 000$ ou sete dias de prisão(CÓDIGO DE POSTURAS MUNICIPAIS DA CIDADE DE VIGIA DE, 1883) ${ }^{3}$.

Cabe ressaltar que calafeto, embora com as restrições impostas se constituiu em um trabalho com técnicas artesanais que atravessaram séculos contribuindo para as dinâmicas da pescaria e das próprias construções de canoas preservando saberes de grupos sociais excluídos pela imposição dos sistemas de poderes locais, entre eles, os hegemônicos formais de produção de conhecimentos.

Figura 1: Vigilenga no calafeto

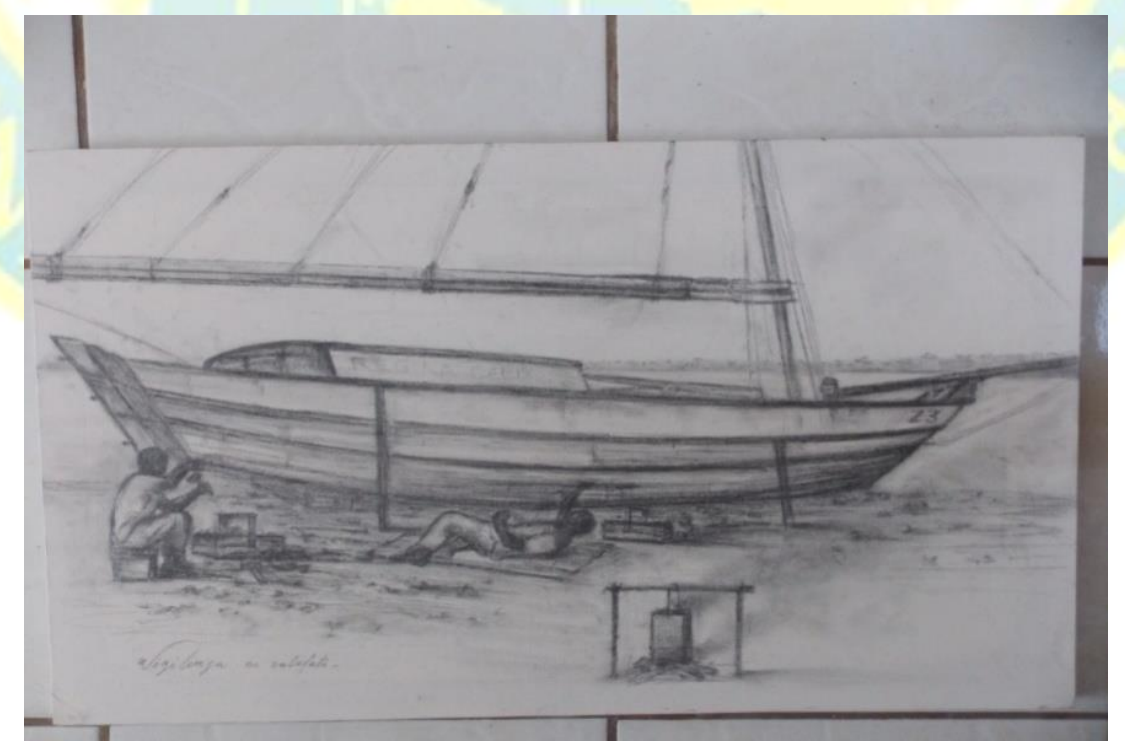

Fonte: Técnica de Grafite sobre papel, artista plástico vigiense Antônio Coutinho, 2016.

\footnotetext{
${ }^{3}$ Código de Posturas Municipal da cidade de Vigia de 1883, encontra-se no Arquivo Público do Estado do Pará em Belém.

Revista do Instituto Histórico e Geográfico do Pará (IHGP), (ISSN: 2359-0831 - on line), Belém, v. 07, n. 02, p. 34 51, jul.-dez. / 2020.
} 


\section{Canoas vigilenas e a dinâmica da pescaria em Vigia, Pará: \\ Saberes e práticas culturais da pesca artesanal}

Neste sentido, os estaleiros ao receberem as vigilengas para reparos, consertos e calafetos se tornavam importantes espaços de circulação de saberes, pois, envolviam as experiências dos trabalhadores dos estaleiros e dos pescadores artesanais, possuindo como elemento aglutinador de produção de conhecimentos as canoas vigilengas.

As vigilengas eram embarcações com formatos arredondados, com proa e popa achatadas e porão aberto, possuindo velas triangulares que eram conhecidas como bujarrona. Estas velas eram confeccionadas em tecido forte de algodão e tingidas com cascas de árvores existentes em manguezais, e cascas da árvore do murici da mata ou murici vermelho, típico da região (LOUREIRO 1985; VERISSIMO 1895).

As velas diferenciadas destas canoas tornaram-se característica marcante nas suas estruturas, o que possibilitava de serem identificadas de longas distâncias quando ao mar, Loureiro (1985) descreve que:

As vilgilengas (de vela triangular) ou as bujarronas (vigilengas de duas velas), embora sejam construídas com matérias primas disponíveis na área, têm sua fabricação obstacularizadas ou dificultadas grandemente pelo fato de que o trabalho necessário à sua confecção é minucioso, demorado e exige grande perícia constituindo-se numa especialização (LOUREIRO, 1985, p. 33).

Portanto, através da confecção das velas para as vigilengas importantes saberes eram desenvolvidos fundamentados em uma relação sociocultural e ambiental, mediadas principalmente pelas coletas e extrativismo de vegetais para tingir as velas e torná-las mais ágeis e seguras na navegação.

Nesta direção Barros (2019) nos relata que as embarcações eram seguras por serem construídas em madeira classificadas como de lei, e sua beleza e estabilidade estavam relacionadas ao formato de suas construções e no talhe dos $\operatorname{mancos}{ }^{4}$, deixando a canoa equilibrada à tona d'água, constituindo uma das principais características das vigilengas. Barros (2019) relata ainda que:

O nivelamento do talabardão ${ }^{5}$ ou tábua, que ia de um extremo a outro dos mancos e que substituía a fasquia ${ }^{6}$, era demasiadamente necessário. "O assentamento da quilha ${ }^{7}$ e sobre ela os braços e cavernas ${ }^{8}$ percintados com dormentes, escoas ${ }^{9}$ e sobre-escoas davam à vigilengas uma acentuada segurança durante as tempestades e no cair na cova das ondas (BARROS, Entrevista, 2019).

\footnotetext{
4 - De acordo com o depoimento do ajudante na construção das canoas Vigilengas, Bartolomeu José de Barros, de 89 anos. Entrevista realizava em julho de 2019, os mancos, era uma peça da madeira piquiá que ficava na frente da canoa.

5 - Talabardão, peça larga que ficava ao lado da canoa, que ia dos mancos centrados na proa a polpa.

6 - Frasquia, madeira que dava forma a canoa.

7 - Quilha, peça estreita que recebia a ponta dos mancos e o braço da canoa.

8 - Caverna, o braço da canoa, ficava centrada na quilha, peça comprida e grossa de piquiá que prende as pontas dos braços.

9- Escoas, prendia a ponta dos braços dos mancos, peça comprida.

Revista do Instituto Histórico e Geográfico do Pará (IHGP), (ISSN: 2359-0831 - on line), Belém, v. 07, n. 02, p. 34 51, jul.-dez. / 2020.
} 


\section{Canoas vigilenas e a dinâmica da pescaria em Vigia, Pará: \\ Saberes e práticas culturais da pesca artesanal}

Figura 2: Vigilenga saindo para a pescaria década de 1950

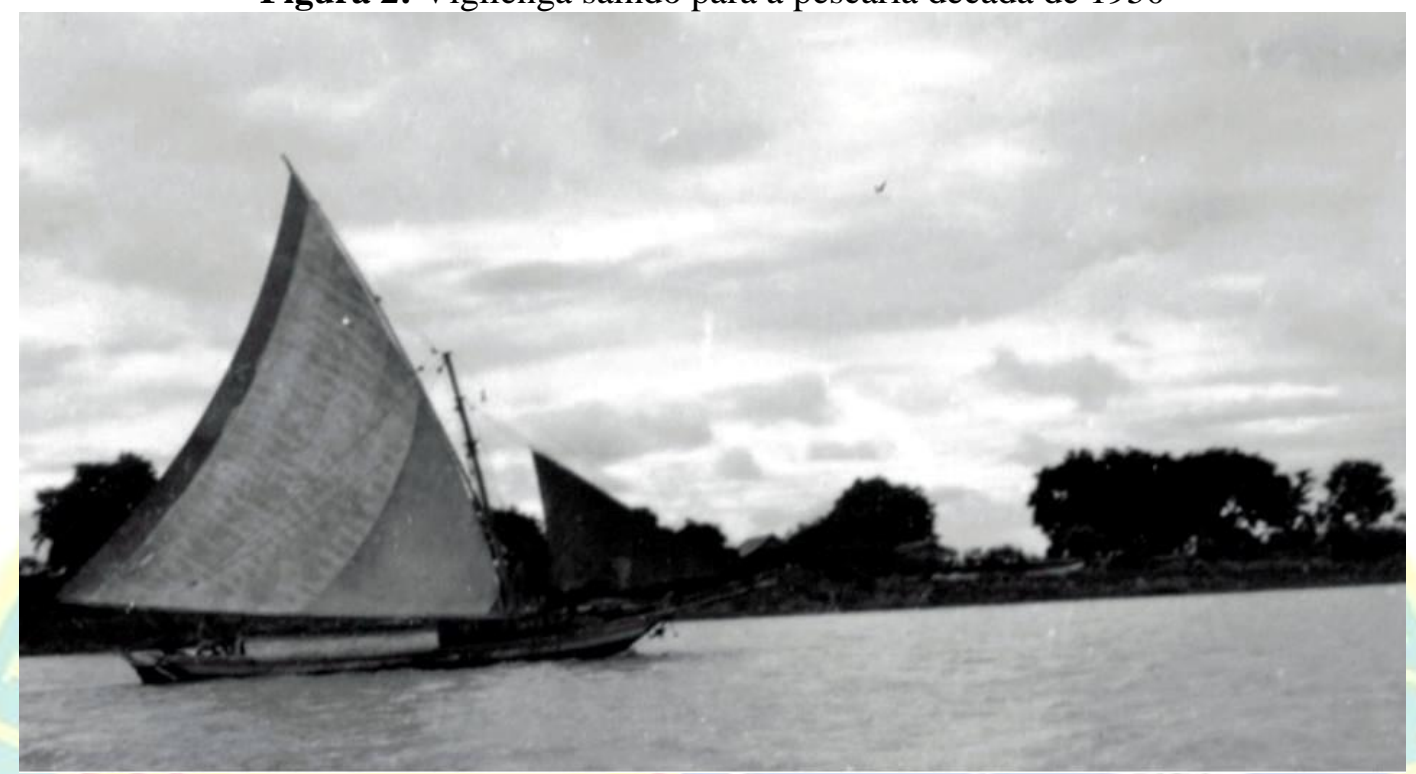

Ainda sobre as características das vigilengas Barros (2009) descreve que:

Tinham o porão aberto, próprio para a coleta de peixes saídos do mar. Um banco de madeira grossa atracava transversamente a canoa, dando-lhe mais segurança e servindo ao mesmo tempo para descabeçamento, corte e lanhação do peixe em fase de beneficiamento. Embaixo do toldo, sobrepostas nos braços e cavernas, tábuas formavam uma estiva, própria para empilhar peixe. Acima dela, na linha do dormente, um assoalho feito de juçara servia de dormitório para os pescadores (BARROS, 2009, p. 23).

Portanto, pode-se compreender que as canoas vigilengas e os estaleiros artesanais responsáveis por suas construções em Vigia no século XIX, tornaram a existência da pesca uma correia de transmissão de conhecimentos que sintetizava as experiências de práticas cotidianas desenvolvidas por atores sociais diversos, como o de calafate, os da carpintaria e o pescador artesanal, apoiados em interações socioambientais locais.

\section{O USO DAS CANOAS E A PESCARIA: UMA JUNÇÃO DE CONHECIMENTOS}

Além da pesca as fabricações de canoas vigilengas tiveram grande importância para a locomoção das pessoas, como não havia estradas rodoviárias o mar era a porta de entrada para chegar à cidade de Vigia, assim sendo, se realizava o transporte de passageiros para cidades próximas e à capital por meio das canoas vigilengas, como pode-se verificar em fragmentos do relatório apresentado ao Sr. Francisco Maria Corrêa de Sá e Benevides, pelo Sr. Pedro Vicente de Azevedo, por ocasião de viagem pela administração da Província do Grão-Pará em 1875:

“O transporte se faz principalmente, em pequenas canoas, denominadas de vigilengas, e no vapor da companhia maranhense, que toca no porto da cidade de mês em mês" (GRÃO PARÁ RELATÓRIO, 1875, p. 77-78). ${ }^{10}$

\footnotetext{
10 - Relatório do Exm. Sr. Dr. Francisco Maria Corrêa de Sá e Benevides. Presidente da Província do Pará, 1875, pp. 77 78.

Revista do Instituto Histórico e Geográfico do Pará (IHGP), (ISSN: 2359-0831 - on line), Belém, v. 07, n. 02, p. 34 51, jul.-dez. / 2020.
} 


\section{Canoas vigilenas e a dinâmica da pescaria em Vigia, Pará: \\ Saberes e práticas culturais da pesca artesanal}

Ainda no século XIX o naturalista Inglês Bates (1944) esteve em Belém em 1848 e ao explorar os arredores da cidade chega até Vigia, se deparando com as canoas vigilengas e seus traços regionais, e de sua constatação relata que:

[...]ao anoitecer passamos por Vigia e Colares, duas aldeias de pescadores, e vimos ali várias canoas nativas, que pareciam de brinquedo em contraste com alto e escuro paredão da mata (BATES, 1944, p. 11).

Não há dúvidas da grande presença das canoas vigilengas no século XIX, se tornando instrumento interações e relações sociais entre pescadores, carpinteiros e comerciantes em Vigia, entretanto é na pesca artesanal que estas canoas se destacaram.

A pesca artesanal é considerada uma das atividades mais antigas exercidas pelo ser humano, esta por sua vez proporcionou aos pescadores adquirir um vasto conhecimento ao longo de vários séculos sobre os aspectos relacionados ao ciclo de vida das espécies capturadas, a época de sua reprodução e a concentração de cardumes (DIEGUES, 2004).

Dentro desta perspectiva que as canoas vigilengas saem dos estaleiros e passam a compor a estrutura de ligação dos pescadores artesanais e as relações iniciais de comercialização do sistema econômico na região.

A pesca tornou-se na Vigia a principal atividade produtiva para os indivíduos aos quais faltam outras qualificações, como o estudo formal, capital suficiente para instalar um pequeno comércio para o fornecimento de gêneros para as embarcações de pesca e aviar as famílias dos pescadores ou ainda carpintaria destinada ao reparo ou construção de barcos, posto que são essas atividades que se destacam na cidade, depois da pesca (LOUREIRO, 1985, p. 58).

Por certo que a pesca artesanal desenvolvida por vários pescadores vigienses, em embarcações vigilengas torna-se a fonte principal de renda e sustentação alimentar de suas famílias.

Nas canoas vigilengas a pesca se caracterizava pelo uso de apetrechos específicos, entre eles o espinhel com anzóis sustentados por boias, as quais sua quantidade dependia da capacidade de cada canoa, onde:

Uma canoa de 600 quilos, geralmente levava 400 anzóis, $n^{\circ} 2$ para a captura de peixes como a gurijuba, mas também vinham outros peixes. As boias eram de cuias, 12 boias para cada aparelho, cerca de 50 anzóis para cada boia. (SILVA, Entrevista, 2018). ${ }^{11}$

No espinhel existia a cada duas braças de linhas esticadas um anzol, a linha era de algodão, essas práticas de pescaria era de pequeno porte, de subsistências conhecida até hoje de chega e vira ${ }^{12}$. Como destaca Silva (2018), um pescador de 80 anos, que passou cerca de 45 anos pescando em canoa Vigilenga:

"Eram as canoas pequenas que traziam os peixes frescos, elas passavam três dias e a última redada vinha o peixe fresco. A maioria das canoas eram salgadeira, com capacidade de até 600 quilos". 13

Nesse contexto, com a grande projeção da pescaria em Vigia e na região amazônica, começou-se a praticar também a pescaria com as canoas freteiras, para fins comerciais, uma espécie de canoa com maiores

\footnotetext{
11 - Depoimento de Álvaro Ferreira da Silva

12 - Pescaria com canoa pequena, com cerca de três ou quatro tripulantes, chagam a pescar no máximo até dois dias.

Traziam o peixe fresco e as pescarias de vários dias e meses traziam o peixe salgado.

13 - Depoimento do pescador Álvaro Ferreira da Silva, de 80 anos. Entrevista realizada em julho de 2018.

Revista do Instituto Histórico e Geográfico do Pará (IHGP), (ISSN: 2359-0831 - on line), Belém, v. 07, n. 02, p. 34 -

51, jul.-dez. / 2020.
} 


\section{Canoas vigilenas e a dinâmica da pescaria em Vigia, Pará: \\ Saberes e práticas culturais da pesca artesanal}

dimensões que atuava coletando o pescado das canoas menores, com pesca desenvolvida por até três meses ao mar, o que propiciou surgir os proprietários de frotas de vigilengas, para os quais, muitos pescadores artesanais passaram a trabalhar (LOUREIRO, 1985).

Percebe-se uma mudança de paradigma no uso das canoas, sendo inserido os elementos do comércio, da exploração dos pescadores para o lucro capitalista o que vai estabelecer novas formas de relações entre os pescadores e agora os donos de canoas vigilengas.

Portanto, há de se destacar que isto não interfere na forma tradicional da pescaria através das canoas vigilengas, requerendo cada vez mais uma profunda relação com os saberes e conhecimentos iniciados na coleta de madeira na floresta e nos estaleiros de construções e reparos.

Destaca-se ainda que por serem canoas produzidas para navegar com o uso de velas, pela força do vento, o conhecimento do ambiente natural como o mar, chuvas, posicionamento dos ventos, se tornava essencial para o saber da navegação ao mar pelos pescadores, que além disso, construíam outras estratégias de sobrevivências como o uso do prumo, apetrecho utilizado para medir profundidade e correntes de marés:

O prumo que nos guiava, se tratava de uma corda com cerca de 12 a 15 braças de comprimento, conforme o tamanho da canoa. O vento também era determinante para as Vigilengas. Em épocas estreladas as estrelas eram os pontos de referências (SILVA, Entrevista, 2018).

Barros (2009), destaca que nas condições formais os pescadores desconheciam as coordenadas, longitude, latitude como meios necessários para a sua localização, mas desenvolviam uma sabedoria secular e de caráter prático, tradicional, transmitida de pai para filho, de uma experiência relacionada com o sol, a lua e as estrelas, que substituía a bússola ou outro aparelho de bordo.

Sem bússola e orientando-se somente a partir do conhecimento do andamento dos astros. Os pescadores sabiam da origem do vento pela bandeirinha a tremular no mastaréu ${ }^{14}$. Na ausência desta, o simples contato com o corpo lhes dava a direção: geral, terral, norte, sul. (BARROS, 2009, p. 23).

Dessa maneira, torna-se perceptível a relação dos pescadores, as canoas e a interação com o ambiente natural como estratégia da pescaria artesanal, em um saber fazer tradicional local, que vai possibilitar a circulação de seus saberes através do conhecimento das condições das marés e do clima, influenciando desta forma na manipulação de apetrechos utilizados nas atividades de pescaria em uma relação dinâmica que unifica conhecimentos ambientais e da pesca no dia-a-dia no mar.

\section{AS MUDANÇAS CONTEMPORÂNEAS NO USO DAS VIGILENGAS}

Com o advento de novos processos econômicos e tecnológicos impostos pela sociedade moderna capitalista como os frigoríficos e a rede de nylon, na segunda metade da década dos anos 1960, se consolida a pesca comercial de grande escala.

\footnotetext{
14 - Mastaréu, tem o mastro, mais à cima a mesa e no final a parte fina é o mastaréu.

Revista do Instituto Histórico e Geográfico do Pará (IHGP), (ISSN: 2359-0831 - on line), Belém, v. 07, n. 02, p. 34 51, jul.-dez. / 2020.
} 


\section{Canoas vigilenas e a dinâmica da pescaria em Vigia, Pará: \\ Saberes e práticas culturais da pesca artesanal}

Logo, altera-se não só a tecnologia da captura e de conservação dos peixes, mas também a arquitetura das embarcações tornando estas dispendiosas financeiramente para adquiri-las, o que vai diminuir o uso das canoas vigilengas e consequentemente suas construções.

$\mathrm{Na}$ verdade, o comércio e as novas tecnologias começam a ditar as novas regras de ir ao mar pescar. Movimentada à vela, a vigilenga tinha arquitetura moldada à pesca de espinhel (linha com centenas e até milhares de anzóis), com produção salgada e estocada no porão das canoas.

Com estas mudanças, não só a arquitetura mudou, mas também as formas de relação com o pescado, o qual vira produção se transformando em mercadoria atendendo a subsistência dos pescadores e o mercado consumidor local e regional.

No século XIX, as construções de canoas se realizavam utilizando ferramentas de uso artesanal e as condições objetivas que vivenciavam tradicionalmente à época possibilitava que os trabalhadores realizassem suas atividades articuladas com os recursos da natureza, o que garantia que seus conhecimentos e saberes das construções artesanais ocorressem em paralelo ao das produções industriais que começava a predominar (LOUREIRO, 1985).

Neste sentido, era possível que pequenos pescadores artesanais como grupos sociais que se estabeleciam de forma heterogênea se tornassem proprietários das canoas vigilengas, dinamizando o uso dos estaleiros na região.

Portanto, a pesca comercial de grande porte insere novos elementos na construção de embarcações que passam a contar com energia elétrica, instrumentos de navegação sofisticados e equipamentos eletrônicos, tornando a construção de barcos e canoas mais complexa envolvendo diversos profissionais como carpinteiros, mecânicos, ferreiros e pintores, visando a construção de veículos de navegação a motor.

Desta forma as canoas vigilengas, com suas enormes velas, deixam de serem fabricadas como nos relata o carpinteiro naval Miranda de 60 anos.

"Há em Vigia, cinco estaleiros em pleno funcionamento, mas hoje, só constroem barcos motorizados, foram-se as canoas de grande porte, porque ninguém mais encomenda vigilenga, por falta de interesse dos pescadores, que só querem barcos motorizados" (MIRANDA, Entrevista, 2018). ${ }^{15}$

\footnotetext{
15. No depoimento do mestre e dono do estaleiro Esperança, Joao Miranda Silva Miranda, 60 anos, diz aprendeu a construir barcos aos doze anos, com o pai, o Mestre Zuza - José Teixeira Miranda, falecido em 2006. Hoje, João tem um estaleiro na Rua Boa Vista, no bairro de Arapiranga, onde trabalham mais cinco operários. Fica à margem de um dos braços do Igarapé da Rocinha e, por isso, de lá não saem barcos acima de 15 toneladas porque não passariam sob a ponte que liga o bairro do Arapiranga ao centro da cidade. Mas no estaleiro do Mestre Zuza, João ajudou a construir barcos de até 70 toneladas. Ele fabrica, em média, até quatro barcos por ano; mas não recebe encomenda de canoa que lembre uma vigilenga. Uma embarcação com o porte de 15 toneladas demora cerca de três meses para ficar pronta. No tempo do Mestre Zuza, demoraria quase o dobro. Só a mão-de-obra custa cerca de R \$ 40 mil. Mas o barco exige mais investimento para ficar completo. A nova geração de embarcações de pesca é equipada com tecnologia de navegação, como o sonar e o GPS (sigla do nome em inglês do aparelho Global Position System, usado até em celular); os barcos maiores recebem antena parabólica para recepção de sinal de TV. Os tempos são outros e nada mais lembra a canoa que era uma marca registrada da cidade de Vigia.
} 
Figura 3: O carpinteiro naval João Miranda, trabalhando na construção de um barco.

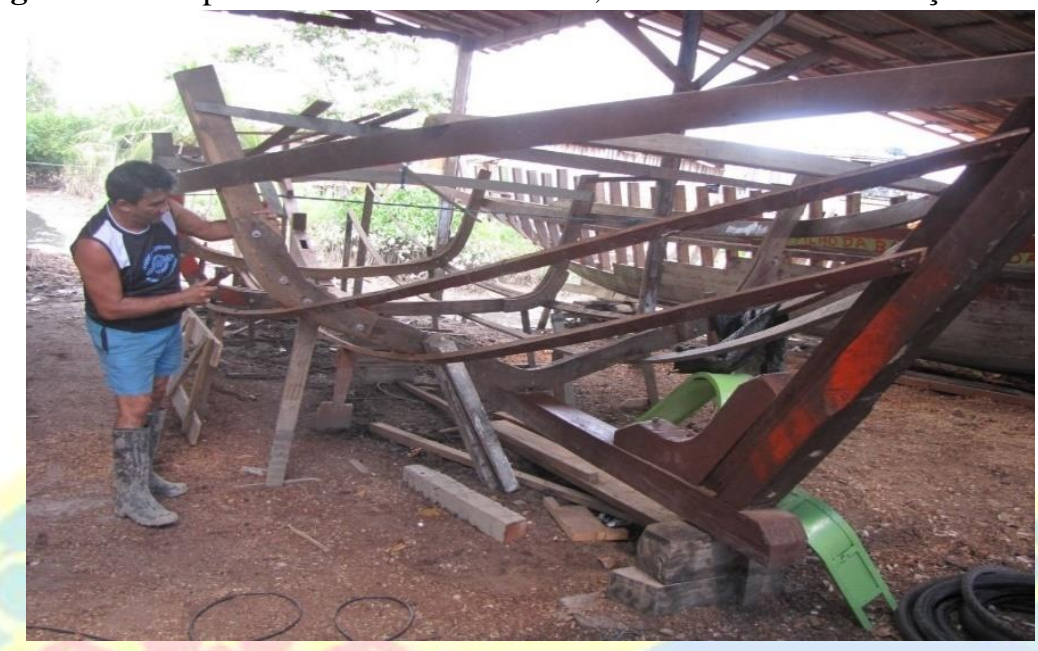

Foto: Tio Rena, 2012.

Assim, o mercado e as imposições sociais do produtivismo da modernidade transformam as realidades locais em Vigia, passando a incentivar relações sociais vinculadas à busca de lucro e o desenvolvimentismo, colocando práticas culturais tradicionais na invisibilidade, como as produções das canoas vigilengas.

De fato, atualmente a globalização econômica apresenta-se como uma retotalização do mundo sob o signo do mercado, negando e reduzindo os potenciais da natureza, esquecendo os saberes tradicionais e subjugando culturas à marginalização (LEFF, 2019).

Logo, as construções das canoas vigilenga, sofrem estas interferências da ação da globalização econômica, entretanto suas técnicas artesanais podem ser percebidas no dia a dia dos estaleiros ainda existentes em Vigia.

\section{CONSIDERAÇÕES FINAIS}

As canoas vigilengas deram uma enorme contribuição para a circulação de saberes e conhecimentos tradicionais em Vigia, que ocorriam em uma dinâmica mediada na relação com o uso das florestas, a partir de práticas culturais ligadas a coleta, e extrativismo de vegetais, necessários ao funcionamento dos estaleiros chegando até à prática da pescaria ao mar.

O uso das canoas vigilengas, influenciou um estilo cultural local, pois, foi só depois que as vigilengas deixaram de ser construídas que as embarcações locais começaram a alterar seus formatos, demonstrando que por séculos elas contribuíram na dinâmica social e prática cultural da região.

Entre as contribuições das vigilengas destaca-se inclusive, o sustento de muitas famílias de pescadores, assim como, o estabelecimento e consolidação das profissões de carpinteiros e calafate que por meio das dinâmicas empreendidas na região, através da pesca artesanal, possuiu um período efervescente no século XIX.

As vigilengas com suas características adequadas à pesca de espinhel com a utilização de velas, viajavam por longas distâncias, pois, só dependia da relação com o ambiente natural (o vento, as marés) para se locomover, o que tornava sua utilização uma fonte de circulação de saberes e conhecimentos entre seus 


\section{Canoas vigilenas e a dinâmica da pescaria em Vigia, Pará: \\ Saberes e práticas culturais da pesca artesanal}

praticantes, envolvendo saberes ambientais, da pesca e as técnicas artesanais da carpintaria naval, como pudemos observar neste trabalho.

Assim sendo, com este estudo sobre o uso das canoas vigilengas, dos estaleiros de suas construções e das relações sociais mediadas em seus diferentes contextos, almejamos contribuir com as reflexões entorno de uma perspectiva que reconheça e valoriza a produção de conhecimentos de comunidades tradicionais na Amazônia, reconhecendo também, as suas formas heterogêneas de organização e de relação com os ambientes naturais que os envolvem.

As vigilengas perderam importância para a perspectiva da modernidade, mas destacaram-se como prática cultural e social que envolveu a região de Vigia, produzindo relações que integraram, em algumas situações, humanos e natureza em práticas cotidianas de circulação de conhecimentos, como no uso de recursos da floresta e a navegação em alto mar.

Portanto, ao se identificar saberes e conhecimentos tradicionais nas dinâmicas das construções de canoas usadas em pesca artesanal em Vigia, envolvendo carpinteiros, pescadores artesanais e o ambiente natural, procuramos tornar evidente os desafios que visem a emancipação social de comunidades tradicionais, a partir da valorização de suas práticas culturais, se contrapondo a imposição de concepções que não reconhecem a história e as formas de produção de conhecimentos que essas comunidades desenvolvem em seus cotidianos na Amazônia.

\section{REFERÊNCIAS}

BAENA, Antônio Ladislau Monteiro. Ensayo corographico sobre a província do Pará. Typ de Santos \& Menor, 1838. 2. ed. Belém: Universidade Federal do Pará, 1969.

BARDIN, Laurence. Análise de conteúdo. São Paulo: Almeida Brasil, 2011.

BARROS, Bartolomeu José de. Vigia de Nazaré: Fragmentos de uma história. Belém: Gráfica-Grafinorte, 2009.

BATES, Henry Walter. O naturalista do rio Amazônia. 2.v. São Paulo: Companhia Editora Nacional/Brasiliana, 1944. 237 p.

BETTENDORFF, João Felipe. Crônica dos Padres da Companhia de Jesus no Estado do Maranhão.2 ed. Belém: Fundação Cultural do Pará Tancredo Neves/Secretaria de Estado da Cultura, 1990. 697 p.

BRASIL. Instituto Brasileiro de Geografia e Estatística. 2019. Disponível em: https://cidades.ibge.gov.br/brasil/pa/vigia/panorama. Acesso em 26 set. 2019.

CARDOSO, Alanna Souto. Apontamentos para história da família e demografia histórica da capitania do Grão-Pará (1750 - 1790). Orientador: Antonio Otaviano Vieira Junior. 2008. 186 f. Dissertação (Mestrado em História Social) -Centro de Filosofia e Ciências Humanas, Universidade Federal do Pará, Belém, 2008. Disponível em: http://repositorio.ufpa.br/jspui/bitstream/2011/4311/1/Dissertacao_ApontamentosHistoriaFamilia.pdf. Acesso em: 28 set. 2019.

CORDEIRO, Paulo. Irmandades Religiosas em Vigia no século XIX. Vigia: Edições do Autor, 2013. 


\section{Canoas vigilenas e a dinâmica da pescaria em Vigia, Pará: \\ Saberes e práticas culturais da pesca artesanal}

DANIEL, João. Tesouro descoberto no máximo rio Amazonas (1722 - 1776). v.2. Rio de Janeiro: Contraponto, 2004. 51p.

DIEGUES, Antonio Carlos. A sócio-antropologia das comunidades de pescadores marítimos no Brasil. Etnográfica, v. 3, n. 2, p. 361-375.Lisboa, 1999.

DIEGUES, Antonio Carlos Sant'Ana. A pesca construindo sociedades: Leituras em antropologia marítima e pesqueira. Núcleo de Apoio à Pesquisa sobre Populações Humanas e Áreas Úmidas Brasileiras. São Paulo: USP, 2004, $315 \mathrm{p}$.

DIEGUES, Antonio Carlos Sant'Ana; PEREIRA, Bárbara Elisa. Conhecimento de populações tradicionais como possibilidade de conservação da natureza: Uma reflexão sobre a perspectiva da etnoconservação. Desenvolvimento e Meio ambiente. v. 22, 2010. Disponível em: https://revistas.ufpr.br/made/article/view/16054. Acesso em: 26 set. 2019.

FLICK, U. Introdução a pesquisa qualitativa. Tradução Joice Elias Costa. $3^{\mathrm{a}}$ ed. dados eletrônicos. Porto Alegre. Artmed. 2013.

GRÃO PARÁ. Código de Posturas Municipal da cidade de Vigia de 1883. Encontra-se no Arquivo Público do Estado do Pará. (Belém).

LEFF, Enrique. Saber Ambiental: Sustentabilidade, Racionalidade, Complexidade, Poder. 11 ed. Petrópolis, RJ: Vozes, 2019. 494 p.

LEFF, Enrique. Epistemologia Ambiental. 4 ed. São Paulo: Cortez, 2007. 239 p.

LOUREIRO, Violeta Refkalefsky. Amazônia: Estado, Homem, Natureza. Belém: CEJUP, 1992. 367 p.

LOUREIRO, Violeta Refkalefsky. Os parceiros do Mar: Natureza e conflito social na pesca da Amazônia. Belém: CEJUP, 1985. 227p.

MARCONI, Marina de Andrade; LAKATOS, Eva Maria. Fundamentos de metodologia científica. -8. ed. [2. Reimp.]-São Paulo: Atlas, 2017. 346 p.

PASCHOAL, Tainá Guimarães. Descobrindo os "tesouros" do jesuíta João Daniel: a mandioca e seu projeto para a Amazônia colonial. Orientadora: Leila Mezan Algranti2018. 262 f. Dissertação (Mestrado em História) - Instituto de Filosofia e Ciências Humanas, Universidade Estadual de Campinas, Campinas, 2018. Disponível em: http://repositorio.unicamp.br/jspui/bitstream/REPOSIP/332074/1/PaschoalTainaGuimaraes_M.pdf. Acesso em: 26 set. 2019.

PROVÍNCIA DO PARÁ. Relatório do Exm. Sr. Dr. Francisco Maria Corrêa de Sá e Benevides. Pará: [s. n.],1875. pp. 77-78.

VERÍSSIMO, José. A pesca na Amazônia. Rio de Janeiro e São Paulo: Livraria Clássica de Alves \& Cia, 1895.

Disponível em: https://digital.bbm.usp.br/handle/bbm/3162. Acesso em 19 set 2019.

VELOSO, Euda Cristina A. Estruturas de apropriação de riqueza em Belém do Grão-Pará, através do recenseamento de 1778. Anais $[S . \quad$ l. $]$, p. 385-407, 2016.Disponível em: http://www.abep.org.br/ abeporgb/publicacoes/index.php/anais/article/viewFile/581/561. Acesso em: 28 set. 2019.

\section{Fontes Orais}




\section{Canoas vigilenas e a dinâmica da pescaria em Vigia, Pará: \\ Saberes e práticas culturais da pesca artesanal}

BARROS, Bartolomeu José de (Ajudante de Construção de canoas), de 89 anos. Entrevistador: Raimundo Paulo Monteiro Cordeiro, Vigia, Julho/2019.

MIRANDA, João Miranda Silva Miranda (Carpinteiro), 60 anos. Entrevistador: Raimundo Paulo Monteiro Cordeiro, Vigia, Julho/2018. 51

SILVA, Álvaro Ferreira da, (Pescador), 80 anos. Entrevistador: Raimundo Paulo Monteiro Cordeiro, Vigia, Julho/2018. 